\title{
Computed tomography findings after head injury preceding chronic subdural hematoma
}

\author{
Kazuki Komiyama, MD, Masahiko Tosaka, MD, Hiroya Shimauchi-Ohtaki, MD, \\ Masanori Aihara, MD, Tatsuya Shimizu, MD, and Yuhei Yoshimoto, MD \\ Department of Neurosurgery, Gunma University Graduate School of Medicine, Maebashi, Gunma, Japan
}

\begin{abstract}
OBJECTIVE Head CT is sometimes performed immediately after minor head injury; however, which cases develop into chronic subdural hematoma (CSDH) remains unclear. Here, the authors retrospectively reviewed the rare cases of CSDH treated surgically in which early head CT had been performed after the initial head trauma.

METHODS A total of 172 patients (133 male and 39 female, median age 76 years) underwent surgery for CSDH at Gunma University Hospital between April 2010 and December 2017. Among these patients were 23 who had visited Gunma University Hospital or a nearby hospital and had undergone head CT within 7 days after the initial head trauma. Characteristics of the initial head CT were examined to identify indicators of subsequent CSDH.
\end{abstract}

RESULTS Among the $23 \mathrm{CSDH}$ cases (17 male and 6 female, median age 80 years), CT scans were obtained on the day of the initial injury (day 0 ) in 19 cases ( 25 sides) and 1-7 days after injury in 12 cases (19 sides); scans were obtained during both periods in 8 cases (12 sides), so that a total of 44 sides were examined. These CT scans were divided into two groups according to when they were obtained; cases in which scans were taken during both periods were included in both groups. Head CT performed on the day of injury showed normal findings in $5(20 \%)$ of 25 sides, thin subdural effusion (SDE) $\leq 6 \mathrm{~mm}$ in $16(64 \%)$ of 25 sides, thick SDE > $6 \mathrm{~mm}$ in $3(12 \%)$ of 25 sides, and acute subdural hematoma (ASDH) in $1(4 \%)$ of 25 sides. CT from 1-7 days after trauma showed thick SDE in $9(47 \%)$ of 19 sides, thin SDE in $8(42 \%)$ of 19 sides, and ASDH in $2(11 \%)$ of 19 sides. A high-density line in the lateral direction (onion skin-like) was found between the skull and the brain in $9(35 \%)$ of 26 sides with SDE on initial CT 0-7 days after the injury.

CONCLUSIONS ASDH was not a common cause of CSDH. Head CT at the time of trauma that precedes CSDH often showed SDE. Such SDE that precedes CSDH was often close to the detection limit of CT immediately after the injury but became more apparent from the day after the injury.

https://thejns.org/doi/abs/10.3171/2019.8.FOCUS19535

KEYWORDS chronic subdural hematoma; subdural effusion; head injury; dura-arachnoid interface layer

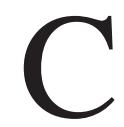
HRONIC subdural hematoma (CSDH) develops over an extended period, but its origin remains unclear despite knowledge of the presenting neurological symptoms, hospital visits, and history of head CT. Consequently, explanations of its origin depend on fragmentary evidence and speculation. The most common proposal for the initiating event has been tearing of a bridging vein, usually caused by prior head trauma and resulting in acute subdural hematoma (ASDH) ${ }^{11}$ Other studies, especially those in Asia, have suggested traumatic subdural hygroma as a predisposing factor., ${ }^{3,716-18}$ Neuroimaging examinations are not often performed early after head injury in patients with CSDH because the preceding head injury is often minor. For this reason, imaging findings before the onset of neurological symptoms are rare in clinical cases. In Japan, head imaging is widespread, and head CT is frequently performed after trauma. ${ }^{19}$

In the present study, we reviewed cases of CSDH surgery in which head CT had been performed after the initial trauma and examined imaging findings for any special indicator of future CSDH.

\section{Methods}

This study was approved by the institutional review board of Gunma University Graduate School of Medicine.

ABBREVIATIONS ASDH = acute subdural hematoma; $C S D H=$ chronic subdural hematoma; $S D E=$ subdural effusion .

SUBMITTED July 1, 2019. ACCEPTED August 16, 2019.

INCLUDE WHEN CITING DOI: 10.3171/2019.8.FOCUS19535. 


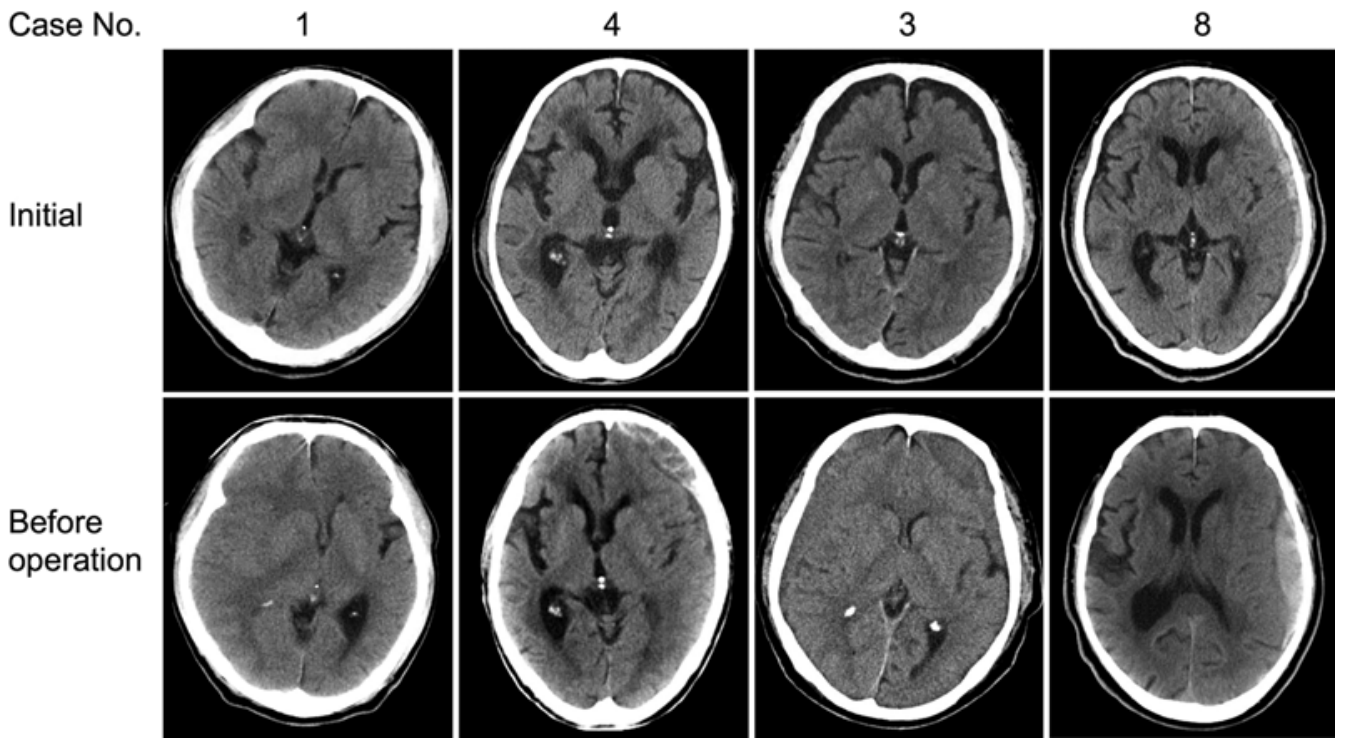

FIG. 1. Initial CT scans (upper) and final CT scans before surgery for CSDH (lower) of representative cases. Each column shows CT scans from the same patient. Initial CT findings were classified by the thickness of SDE: case 1, normal; case 4, thin, $\leq 6 \mathrm{~mm}$; case 3 , thick, $>6 \mathrm{~mm}$; and case $8, \mathrm{ASDH}$.

We reviewed 172 consecutive cases of $\mathrm{CSDH}$ that had been treated with surgery at Gunma University Hospital between April 2010 and December 2017. The 133 male and 39 female patients had a median age of 76 years and had 141 unilateral and 31 bilateral hematomas. All patients underwent surgery as previously described,,$^{21}$ and the postoperative course was good in all cases. One hundred ten cases of CSDH (64\%) were preceded by trauma. Among these cases were 23 patients who had visited our hospital or a nearby hospital because of the initial head trauma and had undergone standard head CT within 7 days after the trauma. The head CT findings for these 23 patients were examined for the present study.

CT was performed at our hospital at the time of the initial injury in 11 cases (48\%). Thin-section $(5 \mathrm{~mm})$ axial scans were obtained through the orbits and globes, with no administration of contrast material. Standard axial CT scans (slice thickness 4-5 $\mathrm{mm}$ ) were taken at another hospital in the other 12 cases (52\%). Head CT scans were obtained again within 7 days after injury in 8 of the 23 cases. Subdural effusion (SDE) was defined according to previously published criteria: ${ }^{16}$ it was identified at the thickest part of the CSDH on preoperative axial CT slices showing the frontal lobe and anterior horn as a band of low density with continuity in a direction parallel to the skull between the skull and the brain and with a clear left-right difference. ${ }^{16} \mathrm{~A}$ high-density line was found in the lateral direction (onion skin-like) between the skull and the brain, and in some cases, the inside was judged as the subarachnoid space and the outside as subdural space. ${ }^{22}$ The maximum thickness of the SDE was classified as thin at $\leq 6 \mathrm{~mm}$ and thick at $>6 \mathrm{~mm}$, as previously reported (Fig. 1). ${ }^{20}$ Standard diagnostic criteria were used for CSDH. In addition, ASDH, traumatic subarachnoid hemorrhage, brain contusion, skull fracture, and facial bone fracture were identified. Two independent observers (K.K. and H.S.O.) examined a total of 76 head CT scans, and the final classifications were determined by consensus.

\section{Results}

Seventeen male and 6 female patients had a median age of 80 years (IQR 63.5-83 years; Table 1). Nineteen patients suffered a fall or tumble, 3 suffered traffic accidents, and 1 had syncope. Seven patients presented with neurological symptoms such as consciousness disorder at the time of initial injury. Eleven patients were hospitalized, and 12 received follow-up home care. The median Glasgow Coma Scale score was 15 (IQR 14-15). Initial CT detected traumatic subarachnoid hemorrhage (3 cases), brain contusion ( 4 cases), and ASDH ( 3 cases, 1 case falx) as intracranial findings. In addition, skull fractures ( 2 cases) and facial bone fractures ( 2 cases) were observed.

Of the $23 \mathrm{CSDH}$ cases, 14 (61\%) were unilateral and 9 (39\%) were bilateral (total of 32 sides). The CT appearance of the hematoma was high density on 6 sides, isodensity on 14 sides, and mixed density on 12 sides.${ }^{14}$ Head CT scans were taken on the day of injury (day 0) in 19 cases (25 sides), on the next day to 7 days after injury (days 1-7) in 12 cases (19 sides), and during both periods in 8 cases (12 sides; Table 1).

The initial CT scans of the 32 sides with CSDH were examined. ASDH was observed on 1 side (3\%), thin SDE of $6 \mathrm{~mm}$ or less on 18 sides (56\%), and thick SDE of more than $6 \mathrm{~mm}$ on 8 sides (25\%). No enlargement of the subdural space was found in 5 sides (16\%; Fig. 1).

The time course of changes ending in CSDH after injury could be observed in 12 sides of 8 cases (Fig. 2). Three sides (cases 2, 9 [right], and 20) showed normal findings on CT immediately after injury, 6 sides (cases 5, 9 [left], 12 [bilateral], and 14 [bilateral]) indicated thin SDE, 2 sides (case 10 [bilateral]) had thick SDE, and 1 side (case 8) had ASDH. Head CT 1 day after injury showed thin 
TABLE 1. Summary of characteristics of 23 patients with CSDH

\begin{tabular}{|c|c|c|c|c|c|c|c|}
\hline \multirow{2}{*}{$\begin{array}{l}\text { Case } \\
\text { No. }\end{array}$} & \multirow{2}{*}{$\begin{array}{l}\text { Age } \\
\text { (yrs) }\end{array}$} & \multirow[b]{2}{*}{ Sex } & \multirow{2}{*}{$\begin{array}{c}\text { Injury } \\
\text { Mechanism }\end{array}$} & \multirow[b]{2}{*}{ Associated Injury } & \multicolumn{2}{|c|}{$\begin{array}{l}\text { CT Performed/Period From } \\
\text { Injury to CT (days) }\end{array}$} & \multirow{2}{*}{$\begin{array}{l}\text { Period From Injury } \\
\text { to Op (mos) }\end{array}$} \\
\hline & & & & & Day 0 & Days 1-7 & \\
\hline 1 & 60 & M & Syncope & Maxillary sinus fracture & Yes & - & 2 \\
\hline 2 & 62 & $\mathrm{~F}$ & Fall & SAH, skull fracture, cerebral contusion & Yes & Yes/1 & 1.5 \\
\hline 3 & 82 & M & Fall & None & - & Yes/2 & 3 \\
\hline 4 & 91 & M & Fall & None & Yes & - & 3.5 \\
\hline 5 & 54 & M & Fall & SAH, ASDH, cerebral contusion & Yes & Yes/1 & 1.5 \\
\hline 6 & 90 & $\mathrm{~F}$ & Fall & None & - & Yes/7 & 2.5 \\
\hline 7 & 97 & $\mathrm{~F}$ & Fall & None & Yes & - & 1 \\
\hline 8 & 83 & M & Fall & ASDH & Yes & Yes/1 & 2 \\
\hline 9 & 84 & M & Fall & Cerebral contusion, skull fracture & Yes & Yes/1 & 3 \\
\hline 10 & 56 & M & Tumble & ASDH, zygomatic fracture & Yes & Yes/4 & 1.5 \\
\hline 11 & 82 & M & Fall & None & - & Yes/1 & 10 \\
\hline 12 & 33 & M & Traffic accident & SAH, ASDH, cerebral contusion & Yes & Yes/1 & 4 \\
\hline 13 & 80 & M & Fall & None & Yes & - & 1 \\
\hline 14 & 61 & M & Fall & None & Yes & Yes/1 & 1 \\
\hline 15 & 87 & $F$ & Fall & None & Yes & - & 1.5 \\
\hline 16 & 83 & M & Fall & None & Yes & - & 2 \\
\hline 17 & 77 & $M$ & Fall & None & Yes & - & 2 \\
\hline 18 & 82 & $\mathrm{M}$ & Traffic accident & None & Yes & - & 3 \\
\hline 19 & 83 & $\mathrm{M}$ & Fall & None & - & Yes/5 & 0.5 \\
\hline 20 & 68 & $\mathrm{~F}$ & Traffic accident & None & Yes & Yes/5 & 1 \\
\hline 21 & 74 & M & Fall & None & Yes & - & 1 \\
\hline 22 & 65 & $M$ & Tumble & None & Yes & - & 2 \\
\hline 23 & 65 & $F$ & Fall & None & Yes & - & 1.5 \\
\hline
\end{tabular}

— = not applicable; $\mathrm{SAH}=$ subarachnoid hemorrhage.

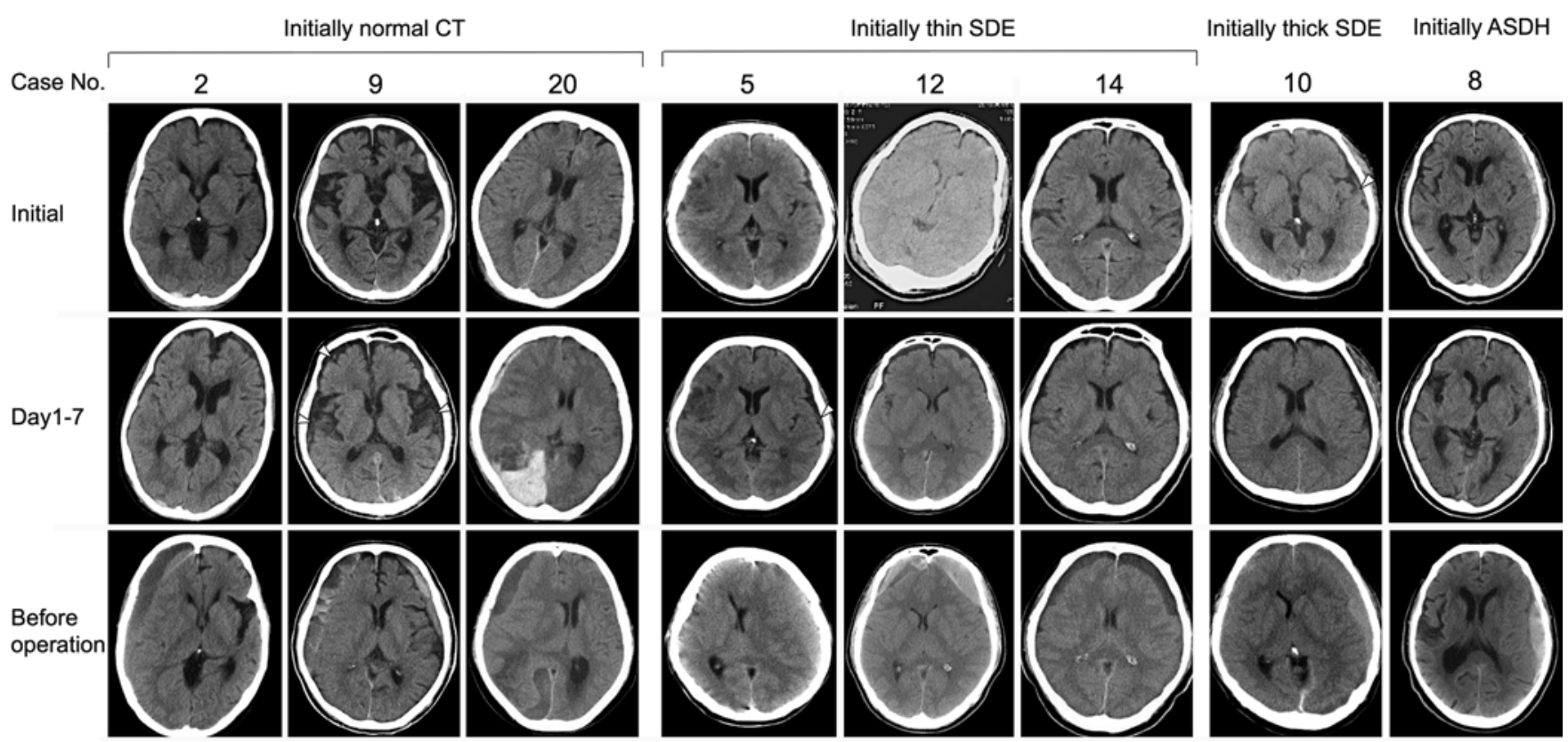

FIG. 2. Time course of CT findings in 8 patients. These patients underwent head CT both on the day of injury (day 0 ) and on the next day to 7 days after injury (days 1-7). Each column shows CT scans from the same patient. Arrowheads in cases 9,5 , and 10 indicate the high-density line of the arachnoid membrane. 
TABLE 2. Summary of CT findings in 23 patients with CSDH

\begin{tabular}{|c|c|c|c|c|c|c|c|}
\hline \multirow[b]{2}{*}{ Case No. } & \multirow[b]{2}{*}{ Side } & \multirow[b]{2}{*}{ CT Density of CSDH } & \multicolumn{2}{|c|}{ Enlargement of Subdural Space on CSDH Side } & \multicolumn{2}{|c|}{ Thickened Arachnoid } & \multirow[b]{2}{*}{ ASDH } \\
\hline & & & Day 0 & Days $1-7$ & Day 0 & Days $1-7$ & \\
\hline 1 & Rt & Iso & No & - & No & - & No \\
\hline 2 & Rt & Iso & No & Yes/thin & No & No & No \\
\hline \multirow[t]{2}{*}{3} & Rt & Iso & - & Yes/thick & - & Yes & No \\
\hline & Lt & Iso & - & Yes/thick & - & Yes & No \\
\hline 4 & $\mathrm{Lt}$ & Mixed & Yes/thin & - & No & - & No \\
\hline 5 & $\mathrm{Lt}$ & Iso & Yes/thin & Yes/thick & No & Yes & No \\
\hline \multirow[t]{2}{*}{6} & $\mathrm{Rt}$ & Mixed & - & Yes/thick & - & No & No \\
\hline & $\mathrm{Lt}$ & Mixed & - & Yes/thick & - & No & No \\
\hline 7 & $\mathrm{Lt}$ & Iso & Yes/thin & - & No & - & No \\
\hline 8 & $\mathrm{Lt}$ & High & Yes/ASDH & Yes/ASDH & No & No & Yes \\
\hline \multirow[t]{2}{*}{9} & Rt & Mixed & No & Yes/thin & No & Yes & No \\
\hline & $\mathrm{Lt}$ & Mixed & Yes/thin & Yes/thick & No & Yes & No \\
\hline \multirow[t]{2}{*}{10} & $\mathrm{Rt}$ & Iso & Yes/thick & Yes/thick & Yes & No & No \\
\hline & $\mathrm{Lt}$ & Iso & Yes/thick & Yes/thick & Yes & No & No \\
\hline 11 & $\mathrm{Lt}$ & Iso & - & Yes/thick & - & Yes & No \\
\hline \multirow[t]{2}{*}{12} & Rt & Mixed & Yes/thin & Yes/thin & No & No & No \\
\hline & $\mathrm{Lt}$ & High & Yes/thin & Yes/thin & No & No & No \\
\hline 13 & $\mathrm{Lt}$ & Mixed & No & - & No & - & No \\
\hline \multirow[t]{2}{*}{14} & $\mathrm{Rt}$ & Mixed & Yes/thin & Yes/thin & No & No & No \\
\hline & $\mathrm{Lt}$ & Mixed & Yes/thin & Yes/thin & No & No & No \\
\hline 15 & $\mathrm{Rt}$ & Mixed & Yes/thick & - & No & - & No \\
\hline 16 & $\mathrm{Lt}$ & Iso & Yes/thin & - & No & - & No \\
\hline 17 & $\mathrm{Lt}$ & High & Yes/thin & - & No & - & No \\
\hline 18 & $\mathrm{Rt}$ & Iso & Yes/thin & - & No & - & No \\
\hline \multirow[t]{2}{*}{19} & Rt & Iso & - & Yes/thin & - & Yes & No \\
\hline & $\mathrm{Lt}$ & Iso & - & Yes/thin & - & Yes & No \\
\hline 20 & Rt & Iso & No & Yes/ASDH & No & No & Yes \\
\hline 21 & $\mathrm{Lt}$ & High & Yes/thin & - & No & - & No \\
\hline \multirow[t]{2}{*}{22} & $\mathrm{Rt}$ & High & Yes/thin & - & No & - & No \\
\hline & $\mathrm{Lt}$ & High & Yes/thin & - & No & - & No \\
\hline \multirow[t]{2}{*}{23} & $\mathrm{Rt}$ & Mixed & Yes/thin & - & Yes & - & No \\
\hline & $\mathrm{Lt}$ & Mixed & Yes/thin & - & Yes & - & No \\
\hline
\end{tabular}

High = high density; Iso = isodensity; Mixed = mixed density.

SDE of $6 \mathrm{~mm}$ or less in 2 sides (cases 2 and 9 [right]), although normal findings had been demonstrated on the day of injury. CT scanning 5 days after injury showed ASDH in 1 side (case 20).

Sides were divided into two groups based on the day on which CT scans had been obtained: group A, CT scans were obtained on the day of injury (day 0); and group B, CT scans were taken 1-7 days after injury (Table 2). Eight cases underwent CT both within 24 hours of injury and within 7 days of injury, so were included in both groups. Analysis of the subdural space was performed in 19 cases with 25 sides in group A and in 12 cases with 19 sides in group B. In group A, 5 (20\%) of 25 sides showed normal findings, 16 (64\%) of 25 sides had thin SDE of $6 \mathrm{~mm}$ or less, 3 (12\%) of 25 sides had thick SDE of more than 6 $\mathrm{mm}$, and 1 (4\%) of 25 sides had ASDH. In group B, no side showed normal findings, 8 (42\%) of 19 sides had thin SDE,
9 (47\%) of 19 sides had thick SDE, and 2 (11\%) of 19 sides had ASDH. These results indicated that normal findings and thin SDE were most common in group A, whereas thick SDE was most common in group B with no normal findings (Fig. 3).

CT scans at the time of injury found a high-density line in the lateral direction (onion skin-like) between the brain and the skull in 9 (35\%) of the 26 sides with SDE, which was thought to be a thickened arachnoid membrane (Fig. 2). ${ }^{22}$ Some sides were considered to have linear and smallscale bleeding. ${ }^{20}$ Local minor bleeding was suspected in 2 sides (8\%; cases 5 and 10), which were not ASDH but rather SDE with suspected microbleeding.

\section{Discussion}

We examined CT scans that had been obtained imme- 


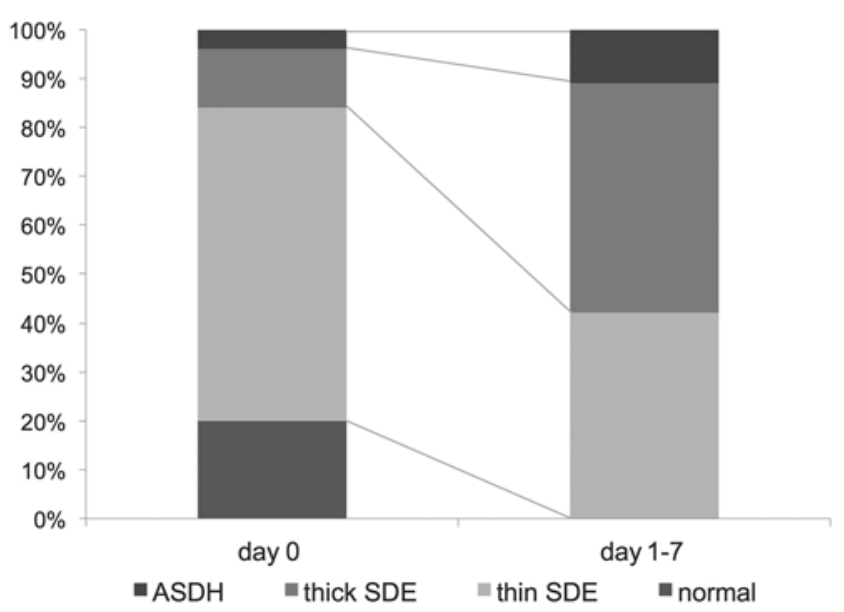

FIG. 3. Comparison of CT findings of normal, thin SDE, thick SDE, and ASDH between day 0 and days $1-7$. Head CT scans taken on the day of injury showed normal findings (20\%), thin SDE of $6 \mathrm{~mm}$ or less $(64 \%)$, thick SDE of more than $6 \mathrm{~mm}(12 \%)$, and ASDH (4\%). CT scans taken 1-7 days after trauma showed thin SDE (42\%), thick SDE (47\%), and ASDH (11\%).

diately after the initial injury in 23 patients ( 32 sides) with CSDH. Initial CT (0-7 days) after injury showed 5 sides $(16 \%)$ with normal findings, 26 sides $(81 \%)$ with SDE, and 1 side (3\%) with SDH. CT performed on the same day as injury mainly showed normal findings or thin SDE, whereas CT performed 1-7 days after injury mainly revealed thick SDE and no normal findings (Table 2 and Fig. 3).

Historically, CSDH was primarily believed to develop from ASDH based on anatomical considerations. ${ }^{2}$ However, head CT has since allowed reliable identification of an interesting pathological condition called "subdural effusion (SDE). ${ }^{7,8,13}$ In one study, CT demonstrated 24 cases of traumatic SDE, which developed into CSDH in 6 cases. ${ }^{24}$ In a subsequent study, CT identification of 43 cases of SDE after trauma revealed a change to CSDH in 13 patients who were older than 65 years. ${ }^{15} \mathrm{CT}$ diagnosis of 58 cases of SDE showed that 19 cases (32.8\%) changed to CSDH. ${ }^{9}$ Three of 169 cases of SDE at the postoperative craniotomy site developed into CSDH. ${ }^{5}$ Recently, $22.7 \%$ of 44 cases of traumatic SDE changed to CSDH. ${ }^{23}$ These reports, mainly from Asia, showed that SDE caused by trauma can develop into CSDH, indicating some consensus (Table 3). ${ }^{3,7,10}$ However, these studies are based on SDE, which is one of the candidates for the origin of CSDH; unfortunately, these studies did not investigate the origin of true $\mathrm{CSDH}$.

CSDH is often treated surgically, so retrospective examination of neuroimages obtained after previous trauma may be helpful in understanding the origin of CSDH. ${ }^{1}$ However, many types of minor injuries may precede $\mathrm{CSDH}$, and many patients do not go to the hospital. In the present study, we retrospectively examined 172 cases of CSDH treated over 7 years, but we found posttraumatic CT images in only 23 cases. Similar studies thus far have included one case report ${ }^{1}$ and a series of only 7 cases. ${ }^{16}$ In the latter study, which involved a review of 37 cases of $\mathrm{CSDH}$, authors found 7 cases with CT (partial MRI) after
TABLE 3. Literature survey of studies on SDE

\begin{tabular}{|c|c|}
\hline Authors \& Year & Results \\
\hline \multicolumn{2}{|l|}{ Subdural hygroma cohort } \\
\hline Yamada et al., 1980 & $\begin{array}{l}6 \text { CSDHs }(25 \%) \text { among } 24 \text { cases of } \\
\text { traumatic SDH }\end{array}$ \\
\hline Ohno et al., 1987 & $\begin{array}{l}13 \mathrm{CSDHs}(30.2 \%) \text { among } 43 \text { cases } \\
\text { of traumatic SDH }\end{array}$ \\
\hline Koizumi et al., 1987 & $\begin{array}{l}3 \mathrm{CSDHs}(1.8 \%) \text { among } 169 \text { cases } \\
\text { of SDH after craniotomy }\end{array}$ \\
\hline Murata, 1993 & $\begin{array}{l}29 \text { CSDHs }(26.9 \%) \text { among } 108 \\
\text { cases of traumatic SDH }\end{array}$ \\
\hline Lee et al., 2000 & $\begin{array}{l}19 \mathrm{CSDHs}(32.8 \%) \text { among } 58 \text { cases } \\
\text { of traumatic SDH }\end{array}$ \\
\hline Wang et al., 2015 & $\begin{array}{l}10 \mathrm{CSDHs}(22.7 \%) \text { among } 44 \text { cases } \\
\text { of traumatic SDH }\end{array}$ \\
\hline \multicolumn{2}{|c|}{ Trauma preceding CSDH cohort } \\
\hline Olivero et al., 2017 & $\begin{array}{l}7 \text { cases w/ CT or MRI at initial } \\
\text { trauma among } 37 \mathrm{CSDHs}\end{array}$ \\
\hline Present study & $\begin{array}{l}23 \text { cases w/ CT at initial trauma } \\
\text { among } 172 \mathrm{CSDHs}\end{array}$ \\
\hline
\end{tabular}

previous trauma. Three of the 7 cases showed enlargement of the unilateral thin subdural space, which was called an "asymmetrically enlarged cerebrospinal fluid intensity extraaxial collection."16 This name seems to be the radiologically correct nomenclature, but we considered this observation to represent thin SDE for the following reasons. Very thin SDE causes thickening of the dura mater to be difficult to distinguish on FLAIR imaging. ${ }^{22}$ Enlargement of the subdural space is probably thought to be continuously thin until the thickening of the dura. Only the presence of the cortical vein sign on preoperative MRI can currently prove that this is the subdural space. ${ }^{12}$ However, the cortical vein sign is only found on MRI, is difficult to identify unless the SDH is thick, and is difficult to see using head CT. But if a thin, asymmetrical, linear cerebrospinal fluid density line is found, it may be considered to be thin SDE if it is linked to future SDE and CSDH over time. This thin SDE can probably be considered as the origin of CSDH (Fig. 4).

The thin SDE as proposed is very thin and is at the boundary between detectable and undetectable on head $\mathrm{CT}$, so may not be pointed out by general neuroradiologists (Fig. 4). ${ }^{16}$ In our study, CT immediately after the trauma most often showed only normal findings or only thin SDE, except for the SDH case (Fig. 4). Therefore, we propose that SDE that subsequently develops into CSDH is often very thin immediately after the injury. Note, however, that CT on the next day and later often detected SDE, so the thickness probably increases over time. In 3 cases (cases 2, 9, and 20), CT on days 1-7 after injury showed enlargement of the subdural space, which had not been seen on the day of injury (Table 2). A previous case had a similar presentation. ${ }^{16}$ Exfoliation of the dura-arachnoid interface layer, which was too thin to be confirmed by CT in the early stages of injury, may be more clearly visualized with time because of the penetration of spinal fluid after trauma ${ }^{6} \mathrm{CT}$ performed $6-46$ days after head injury 


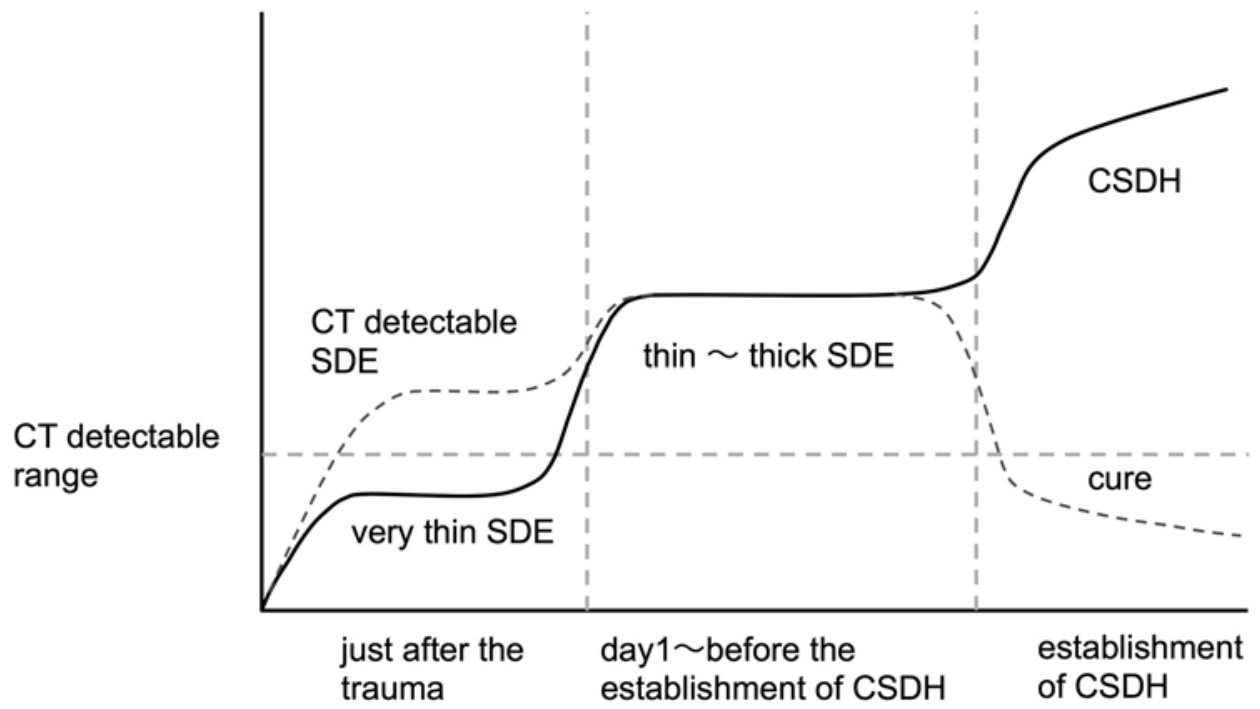

FIG. 4. Graphic illustration showing progression of SDE and detectability of head CT. Thin SDE is considered to be the origin of $\mathrm{CSDH}$. Thin SDE may be at the detectable limit of CT on the day of injury. Subdural hematoma was detectable on CT from the day after injury.

detected SDE in $6.6 \%$ of patients. ${ }^{4}$ Such SDE is expected to develop into CSDH.

The present study of CT after CSDH revealed that the arachnoid membrane at the boundary between the subdural space and subarachnoid space of the brain surface can be identified as a high-density line in some cases. ${ }^{22}$ This high-density line was also seen in the lateral direction (onion skin-like) between the brain and the skull on the initial CT scans in $35 \%$ of cases. The outside of this line may be considered as the subdural space. Minor bleeding was observed in this subdural space in some cases. The subdural space is not a normal anatomical cavity but results from trauma causing exfoliation of the dura-arachnoid interface layer, which may also cause minor bleeding in the subdural space. Thickening of the arachnoid membrane at the boundary between the dura and arachnoid membrane may be associated with trauma sequelae such as linear bleeding.

CT is less likely to be performed after minor head injury, which is considered to be the causative mechanism of CSDH; therefore, few cases are available for study and further investigation is needed. This study was conducted at the university hospital in our territory, which treats a high percentage of cases of severe trauma with extracranial and intracranial injuries and a low percentage of cases of minor head injury, so the characteristics of the general CSDH population and the population of this study may differ slightly.

\section{Conclusions}

We examined CT scans taken immediately after trauma in 23 patients who were subsequently treated for CSDH. Head CT performed on the day of injury most often showed normal findings or thin SDEs of $6 \mathrm{~mm}$ or less or, occasionally, ASDH, but no thick SDE of more than 6 $\mathrm{mm}$. CT performed 1-7 days after trauma mainly showed thick SDE but no normal findings. SDE that precedes
CSDH may be near the limit of detection by CT immediately after injury but becomes more apparent from the day after injury.

\section{References}

1. Atkinson JL, Lane JI, Aksamit AJ: MRI depiction of chronic intradural (subdural) hematoma in evolution. J Magn Reson Imaging 17:484-486, 2003

2. Echlin F: Traumatic subdural hematoma; acute, subacute and chronic; an analysis of 70 operated cases. J Neurosurg 6:294-303, 1949

3. Feng JF, Jiang JY, Bao YH, Liang YM, Pan YH: Traumatic subdural effusion evolves into chronic subdural hematoma: two stages of the same inflammatory reaction? Med Hypotheses 70:1147-1149, 2008

4. French BN, Cobb CA III, Corkill G, Youmans JR: Delayed evolution of posttraumatic subdural hygroma. Surg Neurol 9:145-148, 1978

5. Koizumi H, Fukamachi A, Nukui H: Postoperative subdural fluid collections in neurosurgery. Surg Neurol 27:147-153, 1987

6. Kristof RA, Grimm JM, Stoffel-Wagner B: Cerebrospinal fluid leakage into the subdural space: possible influence on the pathogenesis and recurrence frequency of chronic subdural hematoma and subdural hygroma. J Neurosurg 108:275280, 2008

7. Lee KS, Bae WK, Doh JW, Bae HG, Yun IG: Origin of chronic subdural haematoma and relation to traumatic subdural lesions. Brain Inj 12:901-910, 1998

8. Lee KS, Bae WK, Park YT, Yun IG: The pathogenesis and fate of traumatic subdural hygroma. Br J Neurosurg 8:551558,1994

9. Lee KS, Bae WK, Bae HG, Yun IG: The fate of traumatic subdural hygroma in serial computed tomographic scans. J Korean Med Sci 15:560-568, 2000

10. Liu Y, Gong J, Li F, Wang H, Zhu S, Wu C: Traumatic subdural hydroma: clinical characteristics and classification. Injury 40:968-972, 2009

11. Markwalder TM: Chronic subdural hematomas: a review. J Neurosurg 54:637-645, 1981

12. McCluney KW, Yeakley JW, Fenstermacher MJ, Baird SH, 
Bonmati CM: Subdural hygroma versus atrophy on MR brain scans: "the cortical vein sign". AJNR Am J Neuroradiol 13:1335-1339, 1992

13. Murata K: Chronic subdural hematoma may be preceded by persistent traumatic subdural effusion. Neurol Med Chir (Tokyo) 33:691-696, 1993

14. Nomura S, Kashiwagi S, Fujisawa H, Ito H, Nakamura K: Characterization of local hyperfibrinolysis in chronic subdural hematomas by SDS-PAGE and immunoblot. J Neurosurg 81:910-913, 1994

15. Ohno K, Suzuki R, Masaoka H, Matsushima Y, Inaba Y, Monma S: Chronic subdural haematoma preceded by persistent traumatic subdural fluid collection. J Neurol Neurosurg Psychiatry 50:1694-1697, 1987

16. Olivero WC, Wang H, Farahvar A, Kim TA, Wang F: Predictive (subtle or overlooked) initial head CT findings in patients who develop delayed chronic subdural hematoma. J Clin Neurosci 42:129-133, 2017

17. Park CK, Choi KH, Kim MC, Kang JK, Choi CR: Spontaneous evolution of posttraumatic subdural hygroma into chronic subdural haematoma. Acta Neurochir (Wien) 127:41-47, 1994

18. Park SH, Lee SH, Park J, Hwang JH, Hwang SK, Hamm IS: Chronic subdural hematoma preceded by traumatic subdural hygroma. J Clin Neurosci 15:868-872, 2008

19. Stein SC, Ross SE: The value of computed tomographic scans in patients with low-risk head injuries. Neurosurgery 26:638-640, 1990

20. Tosaka M, Sato N, Fujimaki H, Tanaka Y, Kagoshima K, Takahashi A, et al: Diffuse pachymeningeal hyperintensity and subdural effusion/hematoma detected by fluid-attenuated inversion recovery MR imaging in patients with spontaneous intracranial hypotension. AJNR Am J Neuroradiol 29:1164-1170, 2008

21. Tosaka M, Sakamoto K, Watanabe S, Yodonawa M, Kunimine H, Aishima K, et al: Critical classification of craniostomy for chronic subdural hematoma; safer technique for he- matoma aspiration. Neurol Med Chir (Tokyo) 53:273-278, 2013

22. Tosaka M, Tsushima Y, Watanabe S, Sakamoto K, Yodonawa M, Kunimine H, et al: Superficial subarachnoid cerebrospinal fluid space expansion after surgical drainage of chronic subdural hematoma. Acta Neurochir (Wien) 157:1205-1214, 2015

23. Wang Y, Wang C, Liu Y: Chronic subdural haematoma evolving from traumatic subdural hydroma. Brain Inj 29:462465,2015

24. Yamada H, Watanabe T, Murata S, Shibui S, Nihei H, Kohno $\mathrm{T}$, et al: Developmental process of chronic subdural collections of fluid based on CT scan findings. Surg Neurol 13:441-448, 1980

\section{Disclosures}

The authors report no conflict of interest concerning the materials or methods used in this study or the findings specified in this paper.

\section{Author Contributions}

Conception and design: Tosaka. Acquisition of data: Komiyama, Shimauchi-Ohtaki, Aihara, Shimizu. Analysis and interpretation of data: Tosaka, Komiyama, Shimauchi-Ohtaki. Drafting the article: Tosaka, Komiyama, Shimauchi-Ohtaki. Critically revising the article: Tosaka, Shimauchi-Ohtaki, Aihara, Shimizu, Yoshimoto. Reviewed submitted version of manuscript: all authors. Approved the final version of the manuscript on behalf of all authors: Tosaka. Administrative/technical/material support: Aihara, Shimizu. Study supervision: Yoshimoto.

\section{Correspondence}

Masahiko Tosaka: Gunma University Graduate School of Medicine, Gunma, Japan.nstosaka@gunma-u.ac.jp. 